\title{
Laparoscopic Versus an Open Colectomy in an Emergency Setting: A Case-Controlled Study
}

\author{
Frederick H. Koh ${ }^{1,2}$, Ker-Kan Tan ${ }^{1,2}$, Charles B. Tsang ${ }^{1,2}$, Dean C. Koh ${ }^{1,2}$ \\ ${ }^{1}$ Division of Colorectal Surgery, University Surgical Cluster, National University Health System, Singapore; ${ }^{2}$ Department of Surgery, Yong Loo \\ Lin School of Medicine, National University of Singapore, Singapore
}

Purpose: Laparoscopy continues to be increasingly adopted for elective colorectal resections. However, its role in an emergency setting remains controversial. The aim of this study was to compare the outcomes between laparoscopic and open colectomies performed for emergency colorectal conditions.

Methods: A retrospective review of all patients who underwent emergency laparoscopic colectomies for various surgical conditions was performed. These patients were matched for age, gender, surgical diagnosis and type of surgery with patients who underwent emergency open colectomies.

Results: Twenty-three emergency laparoscopic colectomies were performed from April 2006 to October 2011 for patients with lower gastrointestinal tract bleeding (6), colonic obstruction (4) and colonic perforation (13). The hand-assisted laparoscopic technique was utilized in 15 cases (65.2\%). There were $4(17.4 \%)$ conversions to the open technique. The operative time was longer in the laparoscopic group ( 175 minutes vs. 145 minutes, $\mathrm{P}=0.04)$, and the duration of hospitalization was shorter in the laparoscopic group ( 6 days vs. 7 days, $\mathrm{P}=0.15$ ). The overall postoperative morbidity rates were similar between the two groups $(\mathrm{P}=0.93)$, with only 3 patients in each group requiring postoperative surgical intensive-care-unit stays or reoperations. There were no mortalities. The cost analysis did not demonstrate any significant differences in the procedural $(\mathrm{P}=0.57)$ and the nonprocedural costs $(\mathrm{P}=0.48)$ between the two groups.

Conclusion: Emergency laparoscopic colectomy in a carefully-selected patient group is safe. Although the operative times were longer, the postoperative outcomes were comparable to those of the open technique. The laparoscopic group did not incur a higher cost.

Keywords: Laparoscopy; Colectomy; Emergencies; Case-control studies

\section{INTRODUCTION}

Over the past decade, several large randomized prospective stud-

Received: January 3,2013 - Accepted: January 26, 2013

Correspondence to: Dean C. Koh, M.D.

Division of Colorectal Surgery, University Surgical Cluster, National

University Health System, 1 E Kent Ridge Road, Singapore 119228, Singapore

Tel: +65-67724235, Fax: +65-67778206

E-mail:drdeankoh@colorectalclinic.com

This paper was presented as an oral presentation at the 13th Congress of Asia Pacific Federation of Coloproctology (APFCP) meeting in Bangkok, Thailand, 2-4 December 2011 and as a poster presentation at the 2012 Society of American Gastrointestinal and Endoscopic Surgeons (SAGES) meeting in San Diego, CA, USA, 7-10 March 2012.

(C) 2013 The Korean Society of Coloproctology

This is an open-access article distributed under the terms of the Creative Commons Attribution NonCommercial License (http://creativecommons.org/licenses/by-nc/3.0) which permits unrestricted noncommercial use, distribution, and reproduction in any medium, provided the original work is properly cited. ies have demonstrated the short-term benefits of a laparoscopic over an open colectomy in the elective management of both benign and malignant conditions [1-3]. These advantages included earlier return of bowel function, lower rates of postoperative complications, reduced pain scores and shorter lengths of hospital stay [1-3]. However, the role of the laparoscopic colectomy under emergency conditions remains controversial, with limited data being available in the literature [4-6]. This study aims to describe our experience with laparoscopic colectomies under emergency conditions and to compare the outcomes with those for matched patients who underwent open colectomies.

\section{METHODS}

A retrospective review of all patients who underwent emergency laparoscopic colectomies for various colorectal conditions from April 2006 to October 2011 was performed. The study protocol was reviewed and approved by the Institutional Review Board. 
The surgical conditions included acute lower gastrointestinal hemorrhage, intestinal obstruction and colonic perforation. All the procedures were performed by consultant-grade colorectal surgeons who were experienced laparoscopic colorectal surgeons and had performed elective laparoscopic procedures routinely.

The data collected included age, gender, American Society of Anesthesiologists (ASA) scores and comorbid conditions. In addition, operative findings, types of surgical procedure and operative times, perioperative complications, and lengths of hospital stay were also documented. The severities of complications were graded according to the classification, grade of classification (GOC), proposed by Dindo et al. [7].

Both the hand-assisted laparoscopic (HALS) and the standard laparoscopic (SL) techniques were adopted for use with our patients. Conversion was defined as the need to create an incision that was larger than originally planned in order to perform any part of the operation other than specimen extraction or anastomosis creation [8]. The laparoscopic patients were then matched for age, gender, surgical diagnosis and type of surgery with patients who underwent emergency open colectomies.

A comparison of the cost incurred was performed between the two groups. Total cost included all expenses from the day of admission until discharge. Operating-room charges, procedural costs, consumables and anesthetic medications were tabulated under procedural cost. Nonprocedural cost, as the name implies,

Table 1. Comparison of the demographics and hematological investigations between the two groups

\begin{tabular}{lccc}
\hline Characteristic & $\begin{array}{c}\text { Open group } \\
(\mathrm{n}=23)\end{array}$ & $\begin{array}{c}\text { Laparoscopic } \\
\text { group }(\mathrm{n}=23)\end{array}$ & P-value \\
\hline Age $(\mathrm{yr})$ & $58(20-77)$ & $60(23-79)$ & 0.95 \\
$<40$ & $5(21.7)$ & $5(21.7)$ & \\
$40-60$ & $7(30.4)$ & $7(30.4)$ & \\
$>60$ & $11(47.8)$ & $11(47.8)$ & \\
Male gender & $13(56.5)$ & $13(56.5)$ & 1.00 \\
\hline ASA score & & & 0.65 \\
1 & $6(26.1)$ & $5(21.7)$ & \\
\hline 2 & $9(39.1)$ & $12(52.2)$ & \\
\hline 3 & $4(17.4)$ & $6(26.1)$ & \\
4 & $4(17.4)$ & $0(0)$ & \\
\hline No. of comorbid conditions & $0(0-3)$ & $1(0-4)$ & 0.58 \\
Hypertension & $7(30.4)$ & $12(52.2)$ & \\
\hline Diabetes mellitus & $4(17.4)$ & $5(21.7)$ & \\
Hyperlipidaemia & $6(26.1)$ & $3(13.0)$ & \\
\hline Ischaemic heart disease & $2(8.7)$ & $3(13.0)$ & \\
History of cerebrovascular & $2(8.7)$ & $3(13.0)$ & \\
accident & & & \\
\hline
\end{tabular}

Values are presented as median (range) or number (\%). ASA, American Society of Anesthesiologists. included all expenses incurred outside the operating theater. These included the costs of laboratory and radiological investigations; room charges (from normal ward to high-dependency unit and intensive care unit [ICU]); costs of blood-product transfusions; consultation fees; costs of medications, such as antibiotics and analgesia, and of other consumables, such as invasive lines and syringe pumps; and costs of various therapies, such as physiotherapy.

Categorical variables were compared using the Fisher's exact test while continuous variables were compared using the Mann-Whitney U test. Statistical analyses were performed using the SPSS ver. 17.0 (SPSS Inc., Chicago, IL, USA), and all P-values reported were two-sided with $\mathrm{P}$-values of $<0.05$ being considered statistically significant.

\section{RESULTS}

Twenty-three emergency laparoscopic colectomies were performed for patients who presented with lower gastrointestinal tract bleeding $(n=6,26.1 \%)$, colonic obstruction $(n=4,17.4 \%)$ and colonic perforation $(n=13,56.5 \%)$. The median age of our patients was 60 years (range, 23 to 79 years) with a slight male majority ( $\mathrm{n}=$ $13,56.5 \%)$. Hypertension was the most common comorbid con-

Table 2. Comparison of the operative details between the two groups

\begin{tabular}{|c|c|c|c|}
\hline Characteristic & $\begin{array}{l}\text { Open group } \\
\qquad(\mathrm{n}=23)\end{array}$ & $\begin{array}{c}\text { Laparoscopic } \\
\text { group }(n=23)\end{array}$ & P-value \\
\hline Indication of surgery & & & 1.00 \\
\hline Bleeding & $6(26.1)$ & $6(26.1)$ & \\
\hline Obstruction & $4(17.4)$ & $4(17.4)$ & \\
\hline Perforation & $13(56.5)$ & $13(56.5)$ & \\
\hline Underlying diagnosis & & & 0.69 \\
\hline Appendiceal mass & $7(30.4)$ & $5(21.7)$ & \\
\hline Diverticular disease & $12(52.2)$ & $10(43.5)$ & \\
\hline Neoplasm & $4(17.4)$ & $6(26.1)$ & \\
\hline Postprocedural perforation & $0(0)$ & $2(8.7)$ & \\
\hline Type of surgery & & & 1.00 \\
\hline Right-sided & $14(60.9)$ & $14(60.9)$ & \\
\hline Left-sided & $6(26.1)$ & $6(26.1)$ & \\
\hline Total colectomy & $3(13.0)$ & $3(13.0)$ & \\
\hline Type of laparoscopic technique & NA & & \\
\hline Hand-assisted & & $15(65.2)$ & \\
\hline Standard laparoscopic & $8(34.8)$ & & \\
\hline Conversion to open surgery & NA & & \\
\hline $\begin{array}{l}\text { Significant adhesions+failure } \\
\text { to progress }\end{array}$ & & $4(17.4)$ & \\
\hline Operative time (min) & $145(75-252)$ & $175(104-290)$ & 0.04 \\
\hline
\end{tabular}

Values are presented as number (\%) or median (range). NA, not applicable. 
dition and was seen in 12 patients (52.2\%). The majority of the patients $(\mathrm{n}=11,47.8 \%)$ had an ASA score of 2 . Table 1 illustrates the demographic information of the study group.

The underlying diagnoses included appendiceal masses $(n=5$, $21.7 \%$ ), complicated diverticular disease (perforation or bleeding) $(\mathrm{n}=10,43.5 \%)$ and neoplasms $(\mathrm{n}=6,26.1 \%)$. Also, 2 patients (8.7\%) had postcolonoscopic perforations (Table 2). HALS was the adopted laparoscopic approach in 15 patients $(65.2 \%)$ while the remaining 8 patients (34.8\%) underwent the SL approach. A right colectomy was performed in 14 patients $(60.9 \%)$ while 3 patients (13.0\%) underwent a total colectomy. The median operative time was 175 minutes (range, 104 to 290 minutes).

There were 4 (17.4\%) conversions to the open technique. One was for dense congenital adhesions at the hepatic flexure that was causing a hairpin loop. The second was due to a failure of progress while trying to dissect around an appendiceal phlegmon which had involved the terminal ileum and the cecum. In another patient, the right ureter was injured during the dissection of an appendiceal mass which was plastered to the posterior wall. This necessitated immediate primary repair over a ureteric stent by the urologist. The last conversion was made because the sigmoid colon was densely adherent to the posterior abdominal wall. This hindered the safe identification of the left ureter and vital structures.

The median length of hospitalization was 9 days (range, 3 to 28 days), with 11 patients (47.8\%) having varying grades of perioperative complications. The majority of them $(n=20,86.9 \%)$ had minor or no complications (GOC 0-II) while 2 patients $(8.7 \%$ ) had grade III complications (Table 3 ). One of them required the insertion of an inferior vena cava filter after developing a postoperative pulmonary embolism and deep venous thrombosis while

Table 3. Comparison of the operative outcomes between the two groups

\begin{tabular}{lccc}
\hline Characteristic & $\begin{array}{c}\text { Open group } \\
(\mathrm{n}=23)\end{array}$ & $\begin{array}{c}\text { Laparoscopic } \\
\text { group }(\mathrm{n}=23)\end{array}$ & P-value \\
\hline $\begin{array}{l}\text { Duration of hospital stay (day) } \\
\text { Grade of complication }\end{array}$ & $7(3-31)$ & $6(3-28)$ & 0.15 \\
\hline I & $10(43.5)$ & $12(52.2)$ & 0.93 \\
I & $4(17.4)$ & $3(13.0)$ & \\
II & $6(26.1)$ & $5(21.7)$ & \\
III & $1(4.3)$ & $2(8.7)$ & \\
IV & $2(8.7)$ & $1(4.3)$ & \\
Specific complication & & & \\
Ileus & $7(30.4)$ & $4(17.4)$ & 0.49 \\
Wound complications & $7(30.4)$ & $2(8.7)$ & 0.14 \\
Pulmonary complications & $1(4.3)$ & $4(17.4)$ & 0.35 \\
Reoperation & $1(4.3)$ & $1(4.3)$ & 1.00 \\
Urinary tract infection & $1(4.3)$ & $1(4.3)$ & 1.00 \\
\hline
\end{tabular}

Values are presented as median (range) or number (\%). the other underwent an exploratory laparotomy for a perforation due to an undetected thermal injury to the small bowel. No mortalities were seen in our series.

The laparoscopic group was compared to the 23 matched patients who underwent open colectomies. The demographics, comorbid conditions, surgical diagnoses and procedures were similar (Tables 1 and 2). The laparoscopic group demonstrated longer operative times (175 minutes vs. 145 minutes, $\mathrm{P}=0.04$ ) while the duration of hospitalization was shorter ( 6 days vs. 7 days, $\mathrm{P}=0.15$ ). The severities and the types of perioperative complications were also similar between the two groups $(\mathrm{P}=0.93)$, with the open group having a higher incidence of ileus and wound complications (Table 3).

The median total costs of hospitalization were 11,300 United States Dollars (USD) and 12,360 USD for the open and the laparoscopic groups, respectively $(\mathrm{P}=0.50)$. There were no significant differences in the median procedural costs (3,500 USD [open] vs. 4,050 USD [laparoscopic], $\mathrm{P}=0.57$ ) and the median nonprocedural cost (7,150 USD [open] vs. 8,350 USD [laparoscopic], $\mathrm{P}=$ 0.48 ) between the 2 groups (Table 4 ).

\section{DISCUSSION}

Despite the reported benefits of laparoscopy in the elective management of benign and malignant colorectal conditions, a laparoscopic colectomy performed in an emergency setting remains controversial. Our study was able to demonstrate that this approach can be safely performed by experienced laparoscopists in an emergency setting with acceptable perioperative outcomes. The level of difficulty in each laparoscopic case was carefully matched with a patient who underwent an open colectomy after accounting for age, gender, surgical diagnosis and the procedure performed.

Our study demonstrated that the operative times were longer in the laparoscopic group, but this was associated with shorter lengths of hospital stay and lower rates of complications. These findings were similar to those reported in other comparative studies [4-6]. Marcello et al. [4] demonstrated in a case-control study between the laparoscopic and the open approaches to a total colectomy for acute colitis that the laparoscopic group was associated with ear-

Table 4. Comparison of the cost incurred between the two groups

\begin{tabular}{lccc}
\hline & Open group & $\begin{array}{c}\text { Laparoscopic } \\
\text { group }\end{array}$ & P-value \\
\hline $\begin{array}{l}\text { Procedural cost } \\
\text { (USD) }\end{array}$ & 3,500 & 4,050 & 0.570 \\
$\begin{array}{l}\text { Nonprocedural cost } \\
\text { (USD) }\end{array}$ & $(3,000-8,580)$ & $(3,220-8,420)$ & \\
Total cost of hospitalization & $(1,830-30,150)$ & 8,350 & 0.482 \\
$\quad($ USD) & 11,300 & 12,360 & 0.496 \\
\hline
\end{tabular}

Values are presented as median (range).

USD, United States Dollars. 
lier return of bowel function, shorter length of hospital stay, and fewer complications, albeit with longer operative times. Qazi et al. [9] suggested that straight laparoscopic colectomies in patients with inflammatory bowel disease had a high rate of morbidity, especially in an emergency setting. However, such disease conditions are not as commonly encountered in the Asian context.

$\mathrm{Ng}$ et al. [5] also illustrated similar findings between the laparoscopic and the open approaches in patients with obstructing rightsided colon cancers. The laparoscopic approach was associated with numerous short-term clinical benefits with no compromise to the number of lymph nodes harvested. In another retrospective review, Stulberg et al. [6] demonstrated that the laparoscopic group was associated with earlier return of bowel function, lower number of complications, and shorter hospitalization. The operative time for the laparoscopic group was actually similar to that for those patients who underwent the open approach.

One of the drawbacks of our study was the diversity of surgical indications and diagnoses. This was unavoidable given the limited number of patients in each group. Previous studies on the role of a laparoscopic colectomy in treating patients with acute colitis from inflammatory bowel disease were able to demonstrate the safety, feasibility and benefits of the laparoscopic approach $[4,10$, 11]. The role of laparoscopy in patients with iatrogenic perforation following colonoscopy was also reviewed by Bleier et al. [12]. They found that the laparoscopic approach was associated with fewer complications, shorter lengths of hospitalization and smaller incisions.

The presence of a comparable control group in our study adds to the growing evidence in the literature in support of the role of the laparoscopic colectomy in an emergency setting. However, the importance of the appropriate selection of patients cannot be understated. In our study, no patients in the laparoscopic group had a ASA score of 4. Neither was any patient hemodynamically unstable intraoperatively. Although not addressed in our study, the importance of adherence to standard oncologic principles in cancer surgery must be stressed and will need to be addressed in future studies.

If proficiency in any new technique is to be attained, overcoming the associated learning curve is mandatory. Proficiency in performing a laparoscopic colectomy in an elective setting leads to lower morbidities, shorter operative times and fewer conversions $[13,14]$. Hence, we believe that the advantages demonstrated in elective surgery will likely also be seen for well-selected emergency cases treated by experienced laparoscopic colorectal surgeons. In our study, a lower rate of conversion (1/12 vs. $3 / 11)$ and shorter operative times (158 minutes vs. 180 minutes) were seen in patients who underwent a laparoscopic colectomy during the latter half of the study period. This was reflective of the increased experience attained with time.

Whilst the costs incurred between the two groups were comparable, it was interesting to note that the nonprocedural costs exceeded the procedural costs in both groups. We attribute this to the select group of patients whose conditions in an emergent setting often required additional investigations and medications, closer monitoring in specialized wards, and longer hospital stays compared to patients who underwent elective colectomies. We believe that the short- and the long-term financial benefits that were seen in elective laparoscopic colectomies should also be seen in the emergency setting [15].

Be that as it may, until a well-conducted prospective randomized trial is performed, the role of an emergency laparoscopic colectomy will remain controversial. However, as expertise with the emergency laparoscopic colectomy increases, it is likely to be adopted in highly specialized units.

In conclusion, an emergency laparoscopic colectomy in a wellselected patient group is feasible and safe when performed by an experienced surgeon. Although the operative time was longer, the various postoperative outcomes and the cost incurred were comparable to those of the open technique.

\section{CONFLICT OF INTEREST}

No potential conflict of interest relevant to this article was reported.

\section{REFERENCES}

1. Clinical Outcomes of Surgical Therapy Study Group. A comparison of laparoscopically assisted and open colectomy for colon cancer. N Engl J Med 2004;350:2050-9.

2. Guillou PJ, Quirke P, Thorpe H, Walker J, Jayne DG, Smith AM, et al. Short-term endpoints of conventional versus laparoscopicassisted surgery in patients with colorectal cancer (MRC CLASICC trial): multicentre, randomised controlled trial. Lancet 2005; 365:1718-26.

3. Veldkamp R, Kuhry E, Hop WC, Jeekel J, Kazemier G, Bonjer HJ, et al. Laparoscopic surgery versus open surgery for colon cancer: short-term outcomes of a randomised trial. Lancet Oncol 2005; 6:477-84.

4. Marcello PW, Milsom JW, Wong SK, Brady K, Goormastic M, Fazio VW. Laparoscopic total colectomy for acute colitis: a casecontrol study. Dis Colon Rectum 2001;44:1441-5.

5. Ng SS, Lee JF, Yiu RY, Li JC, Leung WW, Leung KL. Emergency laparoscopic-assisted versus open right hemicolectomy for obstructing right-sided colonic carcinoma: a comparative study of short-term clinical outcomes. World J Surg 2008;32:454-8.

6. Stulberg JJ, Champagne BJ, Fan Z, Horan M, Obias V, Marderstein E, et al. Emergency laparoscopic colectomy: does it measure up to open? Am J Surg 2009;197:296-301.

7. Dindo D, Demartines N, Clavien PA. Classification of surgical complications: a new proposal with evaluation in a cohort of 6336 patients and results of a survey. Ann Surg 2004;240:205-13.

8. Shawki S, Bashankaev B, Denoya P, Seo C, Weiss EG, Wexner SD. What is the definition of "conversion" in laparoscopic colorectal surgery? Surg Endosc 2009;23:2321-6. 


\section{Coloproctology Frederick H. Koh, et al.}

9. Qazi SM, Skovdal J, Munck LK, Bisgaard T. High morbidity after laparoscopic emergency colectomy for inflammatory bowel disease. Dan Med Bull 2011;58:A4326.

10. da Luz Moreira A, Stocchi L, Remzi FH, Geisler D, Hammel J, Fazio VW. Laparoscopic surgery for patients with Crohn's colitis: a case-matched study. J Gastrointest Surg 2007;11:1529-33.

11. Watanabe K, Funayama Y, Fukushima K, Shibata C, Takahashi K, Sasaki I. Hand-assisted laparoscopic vs. open subtotal colectomy for severe ulcerative colitis. Dis Colon Rectum 2009;52:640-5.

12. Bleier JI, Moon V, Feingold D, Whelan RL, Arnell T, Sonoda T, et al. Initial repair of iatrogenic colon perforation using laparoscopic methods. Surg Endosc 2008;22:646-9.
13. Akiyoshi T, Kuroyanagi H, Ueno M, Oya M, Fujimoto Y, Konishi $\mathrm{T}$, et al. Learning curve for standardized laparoscopic surgery for colorectal cancer under supervision: a single-center experience. Surg Endosc 2011;25:1409-14.

14. Kiran RP, Kirat HT, Ozturk E, Geisler DP, Remzi FH. Does the learning curve during laparoscopic colectomy adversely affect costs? Surg Endosc 2010;24:2718-22.

15. Eisenberg DP, Wey J, Bao PQ, Saul M, Watson AR, Schraut WH, et al. Short- and long-term costs of laparoscopic colectomy are significantly less than open colectomy. Surg Endosc 2010;24: 2128-34. 